\title{
Study on Graduates Career Education and Employment Under the New Situation
}

\author{
Bin $\mathrm{Cai}^{1}$ \\ ${ }^{1}$ Graduate School, Capital University of Economics and Business, Beijing 100070, China
}

\begin{abstract} the problem of graduate employment difficulties fundamentally.

\section{INTRODUCTION}

The rapid development and popularization of higher education in China has trained a large number of highly educated talents for the country, which meets the talent demand of employers, but at the same time, some students are hard to find employment. On the issue of graduate employment, because of the exclusion of undergraduate students, junior college students and higher vocational students and even doctoral students, its position is very awkward, can be said to be more than the upper and lower than the lower. Therefore, matching students' abilities accurately with employment needs has become the main method for solving graduate employment problems. It is very necessary to establish and perfect the employment education system for college students.
\end{abstract}

Under the new situation of economic stability and seeking progress, the employment situation of graduate students has experienced an unprecedentedly severe situation, which is aggravated by the utilitarian phenomenon, the lack of good faith concept, the weak moral concept and the need for further improvement of psychological quality.This paper first analyzes and discusses the problems in graduate employment, then explains the important role of graduate career education in employment, and expounds how to make it better in the process of graduate employment, career selection and so on, hoping to provide a reference for solving

Keywords: Graduate Student, Employment Education, Problems and Countermeasures

\section{LITERATURE REVIEW}

Scholars have done a lot of research on the construction of vocational information collection and employment public service platform. Cai Nianhui pointed out in the study of employment problems and countermeasures for graduate students of master's degree that career education is a new educational philosophy, integrating the concept of career education in the course of learning, from kindergarten to adult, including career awareness, career exploration, value clarification, decision-making technology, career orientation and career preparation, etc. ${ }^{[1]}$ on Modern Business Industry,2010-16(165). Xiao Nan pointed out in the path analysis of graduate career planning education that graduate career planning education is to mobilize the subjective initiative and internal potential of graduate students, so that they can find their own shortcomings in the process of job search, so that they can accurately position themselves in the process of career selection through long-term rational planning ${ }^{[2]}$, on Literature and Education Materials, 2016(17).

\section{CURRENT BASIC SITUATION OF GRADUATE EMPLOYMENT IN CHINA}

The highest level of personnel training in higher education is graduate education, which is divided into master's degree and doctoral students. For master's graduates, the threshold of posts in institutions such as colleges or research institutes requires doctoral graduates, so most master's graduate students can choose only enterprises or institutions after graduation; for doctoral graduate students, they have the qualifications to enter universities or research institutes, but the pressure of competition is great, and the difficulty of employment is increased. In addition, there is still a phenomenon of "available undergraduate students do not need graduate students" in enterprise recruitment, so the employment pressure of graduate students is huge and the employment situation is severe. Graduate employment has experienced the changes of package distribution system, merit-based employment system and two-way selection system, and the state's macro-control has become weaker and weaker on the issue of graduate employment. At the same time, due to the change of market supply and demand, that is, the blowout development of graduate education talents, more and more graduate students have been hired low, partial employment and other phenomena.Specifically, the main problems in the process of graduate employment are:

\subsection{Employment Distribution is Uneven, Greatly Influenced by Academic Background}

Under the influence of market economy and supply and demand structure, it is easy to focus on the more developed 
regions. For example, cities such as Shanghai and Beijing have always been the hot regions. Concentrated employment has led to higher employment thresholds in some cities. Some enterprises in the selection of talent will also take the first degree as one of the reference, or the gender of graduate students as an important reference, which makes the employment difficulties of master's graduates, especially female masters, worse.

\subsection{Problems of Graduate Career View}

In the process of graduate employment, many students will feel that they are highly educated and highly skilled personnel, it is difficult to put aside their position to apply for some of the national economy and people's livelihood and enhance the country's comprehensive competitiveness of the conditions of hardship or pay slightly worse, utilitarian phenomenon is serious. In addition, many graduate students in the process of employment in order to improve their own competitiveness there is a phenomenon of false academic qualifications, or in the early stage of employment choose to obtain employment qualifications through interpersonal relations, bribery and other means, a serious lack of integrity awareness and professional ethics. Finally, many graduate students' psychological bearing ability is poor, because the graduate students have been in the campus environment for nearly 20 years, lack of practical life experience, resulting in their ability to bear setbacks is poor, facing the loss in the process of employment and shadow at a loss.

\subsection{Career Planning Education is Weak, Lack of Rational Employment Concept}

For the career education planning of college students, our country started late, on the one hand, because of the large demand for talents in the initial stage, there are few problems of difficult employment, on the other hand, because of the rapid development of higher talent education in our country, the problem of employment education of college students has lagged behind. For graduate education such as the training of high-level professionals, whether training units or graduate students themselves have not given enough attention to the training of job-seeking ability. In the process of graduate employment, there is a phenomenon of blind delivery of resume or interview experience, so it is difficult to realize rational or planned application.

\subsection{Changes in the Concept of Talent Consumption in Employers}

Under the background of promoting higher education vigorously in our country, the blowout of highly educated talents makes the hardware requirement of graduate students increase year by year. The minimum requirements of large enterprise units for master's graduates are basically limited to "211 Project" universities, and even require double "211 Project" universities' study experience both in undergraduate and graduate, the phenomenon of graduate scarcity has long ceased to exist. In addition, because there are some differences between the training mode of master's degree graduate students and the demand of enterprises, enterprises may prefer more plastic undergraduate students when choosing talents, and the cost of enterprises paying for undergraduate students is lower, which is also one of the important problems in the process of graduate employment, and also shows the disconnection between graduate training and social needs.

\section{IMPORTANCE AND NECESSITY OF GRADUATE CAREER EDUCATION}

\subsection{Importance of Graduate Career Education}

In the current society, the number of graduate students has increased rapidly, and the employment problem of graduate students is generally difficult and poor in employment ability. In order to better solve the problem of graduate employment, so that graduate students in employment or career issues more rational, the importance of postgraduate career education is increasingly prominent. Students often have less experience in employment and career selection, it is easy to take a detour because they do not recognize the employment situation; or because of the rush of employment and fail to set up the correct view of employment and career selection, it is difficult to make the correct career planning in the face of future development. All the above problems need to be solved through the development of graduate career education.

\subsection{Necessity of Graduate Career Education}

The graduate career education is also beneficial to improve the graduates' ability of employment and career selection. Through two, three or four years of study, graduate students improve their scientific research ability and pioneering thinking ability, but their social practice ability is relatively poor, and most people have the phenomenon of disconnection between their major and social needs. Graduate career planning can help graduates to analyze the current situation and explore the core competitiveness of graduates, improve the success rate of employment. In addition, through career planning education, graduate students can further consolidate their professional knowledge on the basis of a clearer understanding of themselves, clear industry development prospects and do a good job of rational career planning. In short, the development of graduate career planning education is helpful to the improvement of employment quality and employment rate of college graduates. 


\section{IMPLEMENT THE "THREE FULL EDUCATION" MECHANISM TO PROMOTE GRADUATE EMPLOYMENT}

When we realize the necessity and importance of graduate employment, universities are faced with how to better carry out graduate employment education. On the one hand, we can absorb the mature foreign employment education theory and experience; on the other hand, we should carry out the "three full education" mechanism according to the present situation of our graduate students, follow the guiding principle, the principle of stratification, the principle of science, the principle of full staff, and constantly improve the content system of graduate employment education. Specific measures are proposed as follows:

\subsection{Full Tracking and All-round Training}

Graduate employment is not only carried out in the period of graduation, relying on short-term training is difficult to achieve better results. From the date of admission to graduate school, students should be trained and educated throughout the postgraduate stage according to the characteristics and interests of different students, so as to follow up the service. For the employment guidance of graduate students, its content should also be comprehensive and all-round, and should cover many aspects, such as the education of professional ideal and professional ethics, the guidance of career planning, the education of job selection and career view, and the cultivation of professional ability ${ }^{[3]}$. In order to improve the feasibility of post-graduate employment education, the earlier the work, the better, and can rely on the existing education system, through the development of elective courses and practical activities to identify students' professional interests and cultivate them. At the same time, it is necessary to further strengthen the mental health education of graduate students, improve the mental health education and psychological counseling service system of graduate students, and enhance the ability of psychological adjustment in employment ${ }^{[4]}$.

\subsection{Rely on the Second Class to Enhance the Effectiveness of Graduate Employment Education}

The second class, such as social practice activities and campus cultural activities, as well as employment guidance lectures is to carry out graduate employment education ${ }^{[5]}$. Among them, social practice is an important way to cultivate the social adaptability, innovation ability and practical ability of graduate students. The form of social practice can be employment probation, social research, professional practice and other forms. Through the theoretical study on campus and the practice in the enterprise, students not only enhance their professional ability, but also enhance their employment competitiveness.

\subsection{Establishment of Highly Qualified Employment Guidance Teams}

In order to ensure the quality of graduate education, help graduates better understand their own professional knowledge system and set up a correct concept of employment, employment guidance teachers should not only have a corresponding understanding of the employment situation and policies and regulations, but also master a large number of real-time employment information and students' quality development and psychological counseling skills. Employment guidance teachers should also master certain professional evaluation and vocational counseling related knowledge. To this end, we should first strengthen the professional training of employment guidance teachers, and organize teachers to participate in the recruitment process of enterprises, so as to provide students with better employment training and guidance.

\subsection{Create a Good Hardware Environment for Graduate Employment Education}

First of all, for graduate employment education, school leaders should pay enough attention and give corresponding support in terms of venues, funds and equipment. Schools should create a good communication environment for employment guidance teachers and graduates, such as assisting the work of employment guidance centers through the establishment of associations such as "career clubs" and "career development and employment guidance associations". Through the development of employment education guidance, the graduates' pursuit is gradually turned to "whether they can get exercise in the company ", "whether there are training and learning opportunities in the company" and so on, so that they can face the career changes more calmly in the future career development road, and can more consciously use the development opportunities brought by the career changes to accumulate professional experience.

\section{CONCLUDING REMARKS}

At present, the problem of difficult employment of graduate students has attracted more and more attention from all walks of life. As a high-level talent, graduate students' employment success or failure is even linked to social stability. Under the new situation, it is of great significance to improve the success rate of graduate employment through the development of employment education. On the premise of summing up and absorbing the experience of mature employment education abroad, we put forward some relevant measures on how to carry 
out the work of graduate employment education, hoping to finally realize the goal of graduate employment education guided by the theory of career development.

\section{ACKNOWLEDGMENT}

I would like to extend my sincere gratitude to Mr. Bo Feng, for his instructive advice and useful suggestions on my paper. I am also deeply indebted to all the other teachers in Graduate School for their direct and indirect help to me. Finally, I am indebted to my family for their continuous support and encouragement.

\section{REFERENCES}

[1] Cai Nianhui, Research on employment problems and countermeasures of graduate students. Modern commerce and industry, 2010(16).

[2] Xiao Nan, On the educational path of graduate career planning. Cultural and educational materials, 2016(17).

[3] Zhang Jie, Exploration of Precision Employment Guidance Mode for Graduate Students of Finance and Economics from the Perspective of Career Planning. Contemporary Education Research and Teaching Practice, 2020(06).

[4] Luo Rui. Qi Wenjing.Wang Xue, Investigation, Analysis and Optimization Strategy of Employment Psychology of Full-time Graduate Students -- Taking Beijing Agricultural College as an example. Education Modernization, 2019(73).

[5] Wang Yingquan, Study on the Activity Content of the Second Class and its Role in Education. Journal of Shangluo Teachers College, 2000(01) 